\title{
AUTOMATIC SYSTEM FOR CONTINUOUS MONITORING OF INDOOR AIR QUALITY AND REMOTE DATA TRANSMISSION UNDER SMART_RAD_EN PROJECT
}

\author{
Arthur TUNYAGI ${ }^{1,2}$, Tiberius DICU ${ }^{1}$, Kinga SZACSVAI ${ }^{1}$, Botond PAPP ${ }^{1}$, \\ Gabriel DOBREI ${ }^{1}$, Carlos SAINZ ${ }^{1}$, Alexandra CUCOŞ ${ }^{1 *}$
}

${ }^{1}$ Babeş-Bolyai University, Faculty of Environmental Science and Engineering, "Constantin Cosma" Radon Laboratory, Fântânele No. 30, 400294 Cluj-Napoca, Romania

${ }^{2}$ Babeş-Bolyai University, Faculty of Physics, Str. Mihail Kogălniceanu nr. 1, 400084 Cluj- Napoca, Romania

*Corresponding author: alexandra.dinu@ubbcluj.ro

\begin{abstract}
In September 2016, the SMART-RAD-EN Project was launched, funded by the Competitiveness Operational Programme 2014-2020 of Romania, to be developed up to the year 2020. The ambitious overall objective is focus on to the concept of "smart city" in terms of intelligent integrated solutions, which it aims to achieve in international premiere, in order to improve public health by increasing indoor environmental quality and optimizing the energy efficiency of housing in five urban areas of Romania.

In this study, the current status of the development of the prototype system for continuous monitoring and remote data transmission on radon levels and other household air pollutants (CO2, $\mathrm{CO}$, VOCs and temperature, pressure and humidity sensors) is presented, as an important objective in the frame of the SMART_RAD_EN project. The prototype for intelligent monitoring system was assembled and now is involved in the testing process. Metrology and quality assurance of the prototype system will be carried out within accredited European laboratories and by consulting with the international scientific experts. Remote data transmitted will allow: (1) real time interactive visualization, of the impact of user behavior on indoor air quality; (2) information in case of exceeding threshold levels; (3) to produce estimates of future pollution as a result of the correlation with the meteorological parameters (temperature, pressure and humidity) and user activity. The system, metrological validated, will be implemented in 100 houses with high exposure to radon and other ambient pollutants from the main Romanian urban agllomerations - Cluj-Napoca, Bucuresti, Timisoara, lasi and Sibiu.
\end{abstract}

Key words: indoor radon, prototype system, indoor air quality.

\section{INTRODUCTION}

Optimizing the quality of the indoor environment by monitoring and controlling population exposure to radon and other ambient pollutants in homes, reducing associated health risks by implementing preventive and remedial actions represents a 
global priority (Darby et al., 2006; Field et al., 2006, Council Directive 2013/59/ Euratom; WHO 2009; www.irart.ro; www.smartradon.ro; Cosma and Jurcuţ, 1996; Cosma et al., 2013; Cucoş et al., 2017).

Housing is a very important sector, both from an economic and social perspective, knowing the indoor conditions being a requirement for developing habitat policies. Indoor environmental conditions of housing significantly affect quality of life, manifested by health and intellectual potential, conditions for raising and educating children, safety of daily life and demographic evolution (Pavel et al., 2006).

Indoor air contains a wide range of volatile organic compounds (VOCs) with different chemical and physical properties. Over 900 chemical compounds have been identified in indoor air (Reinhart, 2002). The concentration of these organic compounds depends on many factors (type of activity in the room, ventilation rate, number of occupants, type of furniture, etc.), which makes it extremely difficult to estimate unless they are continuously monitored. Exposure to VOCs has been associated with irritation of mucous membranes (nose, throat or eyes), neurotoxic effects (fatigue, lethargy or headache) or the occurrence of asthma (WHO, 1983). Therefore, monitoring indoor air quality is an extremely important issue and involves the use of precise sensors, able to provide real-time recordings.

Another important factor affecting human health and wellbeing of the occupants of a house is the relative humidity. Studies have pointed out the impact of relative humidity in respiratory infections and allergies (Alsmo and Alsmo, 2014). The relative humidity also affects the rate of formation of formaldehyde, ozone, or salts and acids of sulfur or nitrogen dioxide. In a laboratory study the formaldehyde level tripled by increasing the relative humidity from $30 \%$ to $70 \%$ (Andersen et al., 1976). In a survey of 20 houses, a good correlation was obtained between the concentration of formaldehyde in homes and the relative humidity (IEC Beak Consultants, 1983). The relative humidity is temperature dependent. As the air temperature raises the relative humidity decreases, with significant variations during the diurnal cycle, or between seasons. Epidemiological studies conducted in this direction recommend maintaining humidity in the range $40-60 \%$ to minimize the chances of survival for bacteria and viruses (Alsmo and Alsmo, 2014). Creating a system capable of monitoring temperature and relative humidity and coupling it with ventilation and heating system would maintain moisture in the safe range.

Indoor air quality must be assessed by accurate and representative measurements. Short-term measurements will indicate temporary conditions which are not always representative for long periods of time. Therefore, short-term measurements can lead to false conclusions, reduced performance and unnecessary costs. Therefore, it is recommended the use of systems which allows continuous monitoring, useful both in terms of accuracy and representativeness of results, as well as in establishing the dependency between the monitored factors and occupant activity.

Closely monitoring living conditions and implementing corrective actions where necessary lead, with increased efficiency, to a safe and unmediated improvement of general living parameters, with significant direct and indirect consequences on local and national economic and social development (Pavel et al., 2006). 
The present study pointed out the current status of the development of a Intelligent integrated prototype systems with a low energy consumption for indoor air quality in the SMART_RAD_EN project. This prototype have a vast potential to bring considerable gains in terms of health, research, development and technological innovation. Through their uniqueness on a global scale, both the monitoring and remediation systems resulting from the project and the numerical prediction model for radioactive pollution / contamination of indoor air have the potential to generate additional economic value to the research results, the commercial character being intensively supported by introducing radon legislation in Romania from 2018, according to European norms - DIRECTIVE 2013/59/ EURATOM.

\section{MATERIAL AND METHODS}

The smart pilot prototype for continuous monitoring and remote transmission of data on radon levels and other household air pollutants, which will be designed and developed in the project, will have the following advantages and SMART features, with a high level of innovation, in relation to the current context: premiere.

- The first remote monitoring system of residential radon data, international

- The first intelligent monitoring system, achieved in international premiere, to associated the radon sensor with other household air pollutants ( $\mathrm{CO} 2, \mathrm{CO}$ and VOC) and meteorological sensors (temperature, pressure, humidity) relevant to indoor air quality.

- Choosing methods of remote data transmission requiring a minimum cost of operation.

- Coupling the monitoring station to the existing heating and ventilation unit in the house and start / stop them according to the monitored parameters.

- Continuous monitoring of indoor air quality, basic requirement to obtain the certificate of green house.

- Functionality, mobility, autonomy, high efficiency and relatively low production cost, with a total cost of max. 1000 Euro / prototype compared to complex monitoring stations commercially available

- Broad commercial applicability of the prototype. For the production line of over 1000 pieces component costs are reduced by approx. 30\%, from which we can infer the economy that cheaper equipment can bring.

- An intelligent eco-friendly system with reduced energy consumption compared to existing devices on the market.

- An intelligent but friendly design, both by its size and by the low level of noise. The aim is to miniaturize the integrated system to have as small an impact on housing.

- The system will function as a mediator between user behavior and indoor air quality.

- Designed as a remote monitoring system will allow: (1) real time interactive visualization of user behavior impact on indoor air quality; (2) delivery of statistically credible data; (3) to inform in case of levels exceeding limit with the possibility to highlight periods of abnormal operating conditions, affecting environmental comfort or health 
of residents and thereby to facilitate immediate intervention in case of dangerous accumulation of gases; (4) to produce estimates of future pollution by correlating with meteorological parameters (temperature, pressure, humidity) and behavior.

- The database and server will be as important even after project implementation in that they will provide Romanian and European authorities with relevant indicators on the degree of pollution of indoor environmental quality in connection with energy efficiency in buildings thus providing a bridge between national and international data base.

The proposed monitoring system will include the following hardware and software:

- Sensor for radon;

- Sensors for CO, CO2, VOCs;

- Meteorological sensors for temperature, pressure and humidity;

- Integrated system using on operating system and providing necessary services: analogue and digital data acquisition from the sensors, data transmission via Wi-Fi, local storage of data, implementing control loops and control pumps type actuators, valves; Wireless routers for data transfer via Wi-Fi to a server;

- Server application and web application;

- The client application that allows visualization of data as graphs or tables, setting alarm thresholds and transmitting SMS information with the measurements.

The concentration of radon indoor is influenced by external conditions, such as pressure, temperature, wind strength and direction. For this reason, every city will install an air monitoring station outside.

\section{RESULTS AND DISCUSSIONS}

At present, an intelligent device has been developed in the SMART_RAD_EN project that continuously monitors the concentration of the most frequent and dangerous household pollutants (figure 1).

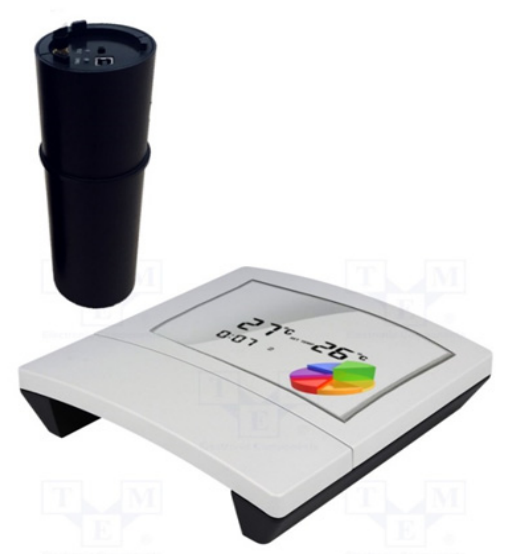

Fig. 1. The SMART_RAD_EN monitoring system. 
The proposed monitoring system architecture is shown in the figure below.

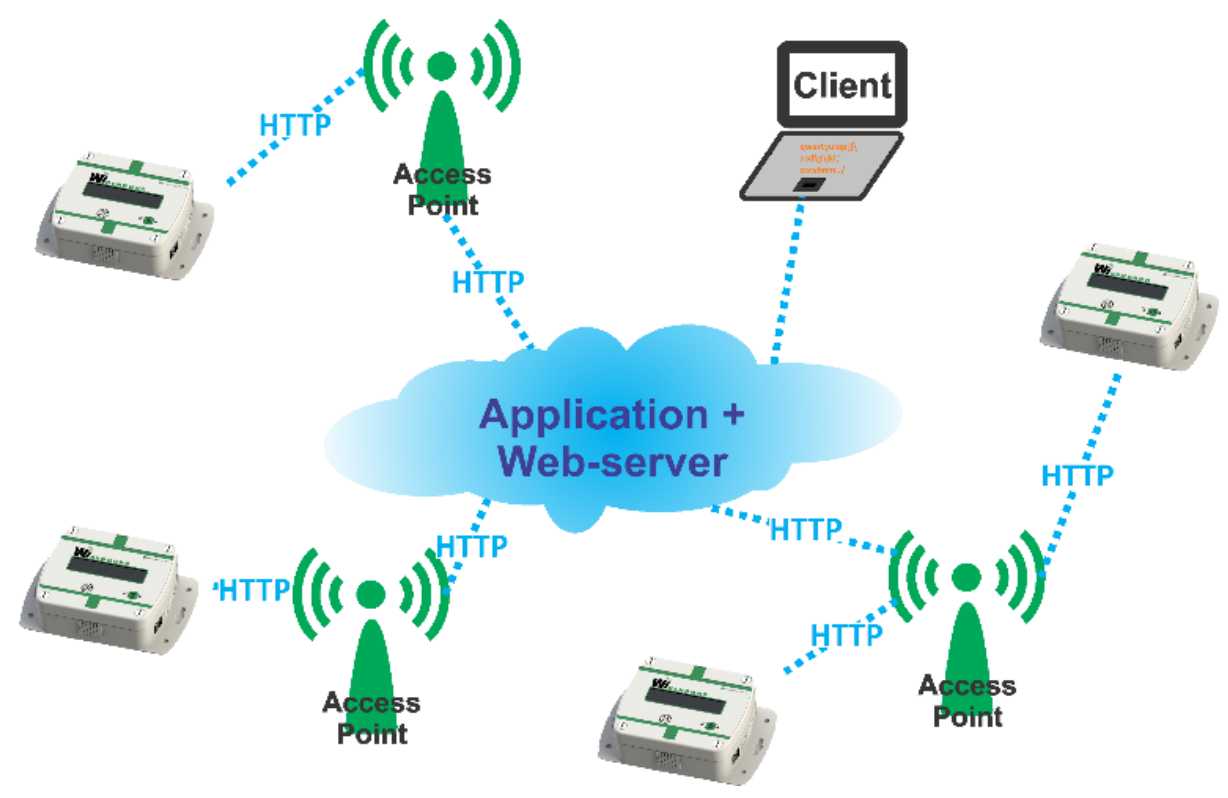

Fig. 2. The general configuration of the monitoring system.

The estimated operating principle of the system proposed for development in this project can be briefly presented based on past experience: indoor radon monitoring will be carried out using a Si-PIN photodiode with a size of $100 \mathrm{~mm}^{2}$, mounted on a fiber glass base, on the surface of which is deposited a thin layer of copper connected to ground. The glass fiber base is placed in a chamber the inner of which is coated with a conductive layer of graphite connected to a positive tension of $250 \mathrm{~V}$. Between the copper layer and the conductive layer is formed an electric field that will allow capture and deposition of radon decay progenies. Alpha particles produced by radioactive disintegration of radon and its progenies penetrate the PIN diode and by the energy released and sent to linked electrons, allow the formation of an electrical impulse across the diode. The measurements data can be stored locally or sent using a wireless connection. The software for the device (firmware) will provide support for the used communication protocol to configure device parameters through a serial communication interface, respectively enable radon measurements and remote data transmission to the destination set. Data will be presented to the user using the concept of loT (Internet of Things).

Environmental conditions influencing diurnal/seasonal variation of residential radon concentration (temperature, humidity and atmospheric pressure) are also measured. In this regard, we will start from the work (Folea and Mois, 2015) describing the authors' contribution to the development of a device for monitoring the ambient 
environment, a device with low power consumption. This paper presents an integrated device closed into a small box, battery powered, with communication capability via Wi-Fi and which integrates $\mathrm{CO}_{2}$, temperature, humidity and pressure sensors. Similar devices are commercially available (Six Point ${ }^{\mathrm{TM}}, 2014$ or ENOCEAN Alliance, 2014), but with lower characteristics and a battery running time reduced. To reduce the power consumption of the final device was chosen a nondispersive infrared sensor (NDIR - Nondispersive Infrared) to measure $\mathrm{CO}_{2}$ with the lowest possible power consumption, available from manufacturers. The developed device, provided with a battery lifetime of up to three years, can measure between 1 and 60 readings per hour. This performance is comparable to most devices with ZigBee ${ }^{\circledR}$ modules, devices consuming less power than Wi-Fi. The device is implemented using PSoC 3 microcontroller 3 (Programmable System-on-Chip) with low power consumption. All sensors integrated into the device have digital interface, providing better measurement precision and simplifying the manufacturing process, in particular by removing the calibration process.

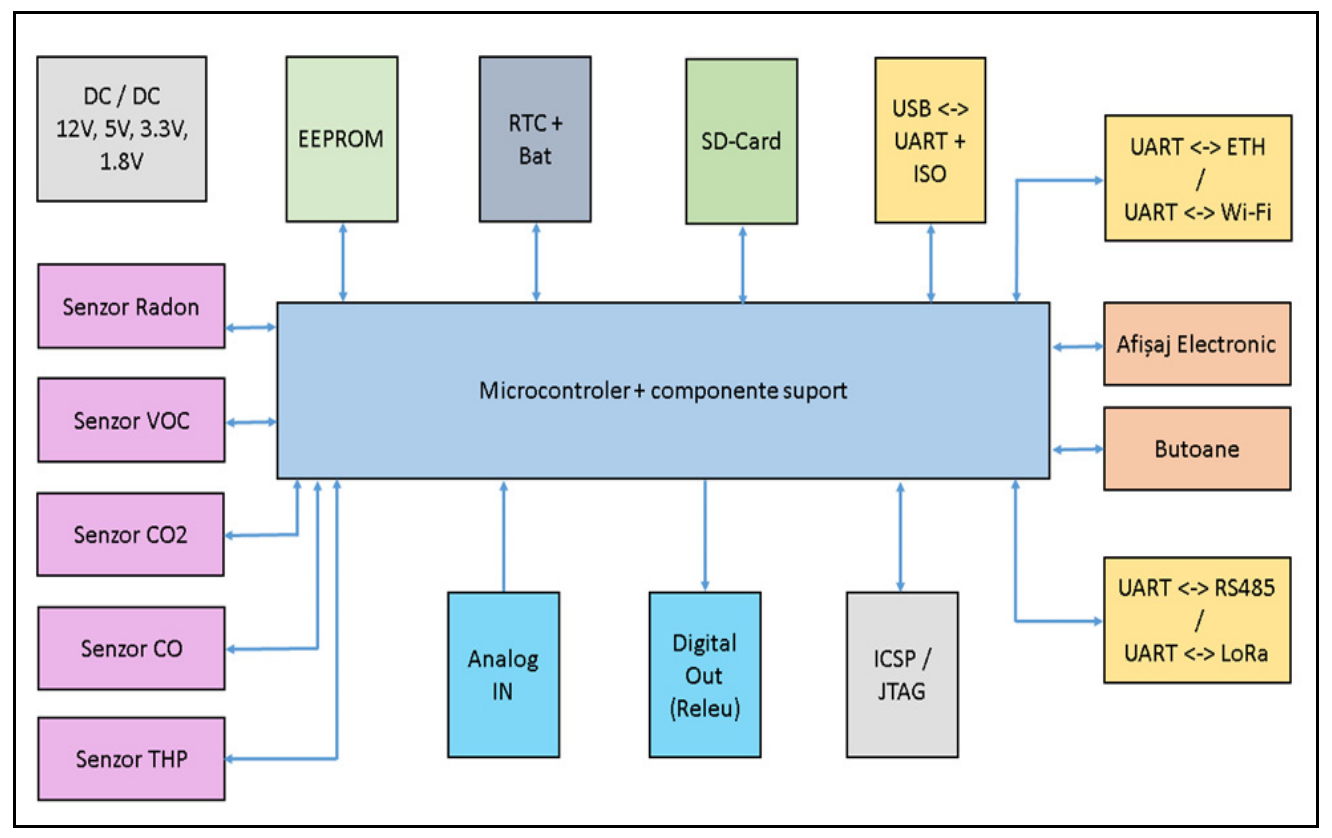

Fig. 3. The general architecture of the monitoring system.

\section{The proposed general architecture}

The device has as a central element an microcontroller AtMega or AtXMega family from Atmel.Blocks attached to the microcontroller are either sensors or specific blocks whose functionality is described below: 
- BLOCK Radon Sensor: is a Tesla TSR2 radon sensor or equivalent that collects the number of specific disintegrations over a certain amount of time. The sensor is interfaced with the microcontroller through a serial port at 3.3V.

- BLOC VOC Sensor: is a volatile MEMS sensor that interferes with the serial port microcontroller at $1.8 \mathrm{~V}$.

- BLOC CO2 sensor: is a CDM7160 carbon dioxide sensor, or equivalent, using the NDIR measurement principle. It interferes with a $5 \mathrm{~V}$ TTL serial port.

- BLOC Sensor CO: is a carbon monoxide sensor of the TGS5141 type or equivalent. The sensor has an analog output, and the internal ADC of the microcontroller is used for measurement.

- BLOC THP sensor: is a sensor or a group of sensors used to measure ambient temperature, humidity and atmospheric pressure. Communication with the microcontroller is done on SPI or I2C depending on the type of sensor / sensors chosen.

- EEPROM BLOCK: is an EEPORM memory used to store the device's set parameters (eg IP server address or SSID credentials for WiFi connection).

- BLOCK RTC + Bat: is the real-time block of the system. The RTC also has a backup battery to keep the time when the unit has a snack. Regular synchronization of the RTC is done online either from the main server or from an NTP.

- SD-Card BLOC: is a block containing an SD-Card that has the role of log memory and where all the results from the sensors as well as the lists with the operating errors are stored.

- USB BLOCK <-> UART + ISO: consists of a UART converter <-> USB (VCP) and galvanic isolation. The USB channel can be used for local device configurations or to download data stored on the SD card.

- UART BLOCK <-> ETH / UART <-> WiFi: is the block through which the device can connect to the internet. Use either a wired or WiFi connection.

- BLOCK Electronic Display: is the display block, state output. It will consist of an LCD or TFT display and some status LEDs.

- BLOCK Buttons: is the input component of the user. It will consist of an On / Off button and a few other menu buttons. The menu buttons can be virtual in the sense that they can be touch buttons if the display is done on a touch-screen TFT.

- UART BLOCK <-> RS485 / UART <-> LoRa: is a block that will be useful to future developments.

The paper presents the main features for each sensor, underlining the important characteristics: measurement range, accuracy, power consumption etc. Each sensor was chosen to have a power consumption as low as possible and meet performance requirements. The measured data are displayed on XivelyTM data server that displays data from sensors connected to the Internet. Upon user's request data can be displayed locally on a backlit LCD. For the CO2 sensor it is also available an automatic calibration option, feature offered by Cozir ${ }^{\circledR}$ manufacturer. 
A small number of companies produce integrated SoC solutions (System on Chip) which integrate a radio module for a Wi-Fi network with low power consumption, an analogue interface for sensors and a user programmable processor for which provides a kit software update and support. This paper proposes multi-level software architecture for a monitoring application and provides detailed block diagrams and application components. There are presented various extension cards, such as: an extension to a weather station that includes sensors for temperature, humidity, light intensity and atmospheric pressure; a sensor for density of the particles of dust in the air and an extension with solar cells as an independent source of power for the weather station, as an alternative source of energy. A digital sensor monitoring wind speed and direction was connected to the Wi-Fi device. It was implemented a new firmware to ensure the functioning of the new developed sensor. Several applications were carried into effect, such as: a first application running on a computer and sending data to a server connected via the Internet, this configuration enables wireless sensors to send data to the Pachube database server to be accessed remotely at any time; a second application running on an Android Smartphone and can communicate with the $\mathrm{Wi}-\mathrm{Fi}$ or the server, allowing, on user's request, local display of sensor data.

\section{CONCLUSIONS}

The proposed monitoring system through the new monitored parameters and by its way of rendering the results will act as a mediator between user behavior and indoor air quality. The owner will be able to understand the effects of his household behavior on indoor air quality and will be able in this way to change his routine in order to increase and maintain indoor air quality to the desired level. Creating a smart prototype system for monitoring air quality (radon, $\mathrm{CO}_{2}, \mathrm{CO}$ and VOC's) and environmental parameters (pressure, temperature and humidity) will raise a number of challenges:

- Calibration and validation of the results obtained by the sensors included in the monitoring system.

- In situ validation of the results by consulting with international experts.

- Create the conditions through presentations addressed to the economic environment in order to introduce the prototype to production/marketing.

\section{ACKNOWLEDGMENTS}

The research is supported by the project ID P_37_229, Contract No. 22/01.09.2016, with the title "Smart Systems for Public Safety through Control and Mitigation of Residential Radon linked with Energy Efficiency Optimization of Buildings in Romanian Major Urban Agglomerations SMART-RAD-EN" of the POC Programme. 


\section{REFERENCES}

Alsmo T., Alsmo C., 2014, Ventilation and relative humidity in Swedish buildings. Journal of Enviromental Protection, 5, pp.1022 - 1036.

Andersen I., Lundqvist G.R., Molhave, L., 1976, The Effect of air humidity and sulphur dioxide on formaldehyde emissions from a construction material (Chipboard). Holzforschung und Holzverwertung, 28, pp.120-121.

Cosma C., Jurcuţ T., 1996, Radon and the surrounding environment. Dacia, Cluj-Napoca, $208 \mathrm{p}$.

Cosma C., Cucoş (Dinu) A., Dicu T., 2013, Preliminary results regarding the first map of residential radon in some regions in Romania, Radiation Protection Dosimetry, 155, pp. 343-350.

Council Directive 2013/59/Euratom laying down basic safety standards for protection against the dangers arising from exposure to ionising radiation (http://www.ecolex.org/ecolex/ ledge/view/RecordDetails;DIDPFDSljsessionid=0143E1A4CE30CABFEEE93B0CE 3BBFFOF?id=LEX-FAOC130004\&index=documents)

Cucoş (Dinu) A., Papp B., Dicu T., Moldovan M., Burghele B.D., Moraru I., Tenter A., Cosma C., 2017, Residential, soil and water radon surveys in north-western part of Romania, Journal of Environmental Radioactivity, 166 (2), pp. 412-416.

Darby S., Hill D., Deo H., Auvinen A., Barros-Dios J.M., Baysson H., Bochicchio F., et al., 2006, Residential radon and lung cancer - detailed results of a collaborative analysis of individual data on 7148 persons with lung cancer and 14208 persons without lung cancer from 13 epidemiologic studies in Europe. Scandinavian Journal of Work, Environment \& Health, 32, pp.1-84.

Field R.W., Krewski D., Lubin J.H., Zielinski J.M., Alavanja M., Catalan V.S., et al., 2006, An overview of the North American case-control studies of residential radon and lung cancer, Journal of Toxicology and Environmental Health, A (69), pp. 599-631.

Folea S., Mois G., 2015, A Low-Power Wireless Sensor for Online Ambient Monitoring, Sensors Journal, 15, DOI: 10.1109/JSEN.2014.2351420.

IEC Beak Consultants Ltd., 1983, Indoor Air Quality, Cambridge Sealed Homes, a Report for Ontario Ministry of Municipal Affairs and Housing, IEC Beak, Mississauga, Ontario.

Pavel V., Vasilache M., Chereches M., 2006, Consideraţii asupra economiei de energie în clădirile din România (1974-2004), Masa rotundă „Dezvoltarea durabilã în construcţii civile sub impactul modificarilor climatice, preţului crescând al energiei şi riscului seismic" organizată de Academia de Ştiinţe Tehnice, Universitatea Tehnică "Gh. Asachi" Iaşi, Inspectoratul de Stat în Construcţii, laşi, 19 mai 2006.

Reinhart C.F., 2002, The Future for renewable energy 2. James \& James Science Publishers, London, UK, pp.79-114.

WHO - World Health Organization, 1983, Indoor Air Pollutants: Exposure and Health Effects, EURO Rep. Stud. 78, pp.1-42.

WHO - World Health Organization, 2009, Handbook on indoor radon: a public health perspective, ISBN 9789241547673, pp.1-93.

www.irart.ro

www.smartradon.ro 
